University of Wollongong

Research Online

Faculty of Social Sciences - Papers (Archive) Faculty of Arts, Social Sciences \& Humanities

2018

From troublesome materials to fluid technologies: Making and playing with plastic-bag footballs

Natascha Klocker

University of Wollongong, natascha@uow.edu.au

Paul Mbenna

University of Wollongong

Christopher R. Gibson

University of Wollongong, cgibson@uow.edu.au

Follow this and additional works at: https://ro.uow.edu.au/sspapers

Part of the Education Commons, and the Social and Behavioral Sciences Commons

Research Online is the open access institutional repository for the University of Wollongong. For further information contact the UOW Library: research-pubs@uow.edu.au 


\title{
From troublesome materials to fluid technologies: Making and playing with plastic-bag footballs
}

\author{
Abstract \\ The material recalcitrance of plastic bags - evident in their refusal to decompose and their capacity to \\ evade neat disposal - is a widespread source of environmental concern and frustration. Yet throughout \\ the Majority (developing) World, the incessant materiality of plastic affords boys and young men an \\ opportunity to make footballs (soccer balls) out of waste. Made in situ, plasticbag footballs are uniquely \\ suited to local contexts and landscapes - a resourceful technology assembled from otherwise \\ troublesome materials. Plastic-bag footballs are also fluid: perpetually in-the-making and characterized by \\ diverse states of working order. Insights garnered from discussions with young Tanzanian football- \\ makers and players position plastic-bag footballs against neocolonial discourses of poverty and precarity. \\ Meanwhile attentiveness to the socio-material relations of plastic-bag footballs makes plain that they are \\ not inferior technologies. Plastic-bag footballs invite consideration of how humans live, materially, in the \\ Anthropocene. Plastic bags typify the ecological crises of throwaway consumerism and malignant \\ toxicity. Yet, we ask: could it be that plastic-bag footballs exemplify the material resourcefulness, skill, \\ care for things - and even playfulness - needed to cope with these very crises?.

\section{Disciplines} \\ Education | Social and Behavioral Sciences

\section{Publication Details} \\ Klocker, N., Mbenna, P. \& Gibson, C. (2018). From troublesome materials to fluid technologies: Making and \\ playing with plastic-bag footballs. Cultural Geographies, 25 (2), 301-318.
}




\title{
Klocker, N., Mbenna, P. \& Gibson, C. (2018). From troublesome materials to fluid technologies: Making and playing with plastic-bag footballs. Cultural Geographies, 25 (2), 301-318.
}

\begin{abstract}
The material recalcitrance of plastic bags - evident in their refusal to decompose and their capacity to evade neat disposal - is a widespread source of environmental concern and frustration. Yet throughout the Majority (developing) World, the incessant materiality of plastic affords boys and young men an opportunity to make footballs (soccer balls) out of waste. Made in situ, plastic-bag footballs are uniquely suited to local contexts and landscapes - a resourceful technology assembled from otherwise troublesome materials. Plastic-bag footballs are also fluid: perpetually in-the-making and characterized by diverse states of working order. Insights garnered from discussions with young Tanzanian football-makers and players position plasticbag footballs against neocolonial discourses of poverty and precarity. Meanwhile attentiveness to the socio-material relations of plastic-bag footballs makes plain that they are not inferior technologies. Plastic-bag footballs invite consideration of how humans live, materially, in the Anthropocene. Plastic bags typify the ecological crises of throwaway consumerism and malignant toxicity. Yet, we ask: could it be that plastic-bag footballs exemplify the material resourcefulness, skill, care for things - and even playfulness - needed to cope with these very crises?
\end{abstract}

\section{Keywords}

anthropocene, care, incessant materiality, making, more-than-human, play, postcolonial, resourcefulness, skill, waste

\section{Introduction}

I'm a volunteer at a village primary school in Tanzania's rural southern highlands. It's 2003 and we're organising a 'tamasha' (festival). We need prizes for the students. My colleagues and I head to the closest town, Iringa, to do some shopping. We decide on footballs and netballs. The tamasha is a success, but something happens afterwards. The boys play a football (soccer) match at school. On its very first outing, one of the footballs breaks. Over the coming days, I watch as another football breaks. And then another. Within a week, there are none left. The boys commandeer the girls' netballs. They break too. Someone pulls out a plastic-bag football, and they keep going. (Natascha)

The material properties of the ubiquitous plastic bag have earned it a reputation as an environmental villain. Plastic bags accumulate in the ocean; entangle, choke and kill animals; block stormwater drains and cause floods; provide micro-habitats for disease-spreading organisms; and render landscapes and seascapes visibly and irrefutably polluted. ${ }^{1}$ Plastic bags - particularly the single-use high-density polyethylene (HDPE) variety - have become signifiers of high throughput modes of capitalist consumption: single-use, cheap and flimsy. Rubbish. The enormity of the plastic bag problem is staggering: between 500 billion and one trillion plastic bags are produced worldwide every year. ${ }^{2}$ They are everywhere, floating about and refusing to stay put when humans dispose of them. Their material recalcitrance is perhaps most evident in their failure to decompose, to recognize when we no longer need them, when their work has been done. Plastic bags serve as a highly visible reminder that 'disposability is a technical and spatial fantasy', 3 and that different ways of living with materials are an urgent imperative. 
But we have other, fonder memories of plastic bags - gleaned from years spent living, volunteering, working and researching in Tanzania. There, as in other parts of the Majority World, boys and young men gather discarded plastic bags to make footballs. Paul grew up in Tanzania's largest city, Dar es Salaam, and was one of these boys.

Despite its ubiquity, football-making of this kind has attracted minimal academic attention. ${ }^{4}$ This is in contrast to young Africans' waste picking practices more generally, which have featured in studies concerned with informal waste economies, and scavengers' health and exploitation. ${ }^{5}$ Contemporary studies of African youth - particularly in postcolonial African cities - describe this life stage as an open-ended period of 'waithood', 6 of acting 'at a loss', of 'hustling' to get by and to get things done. ${ }^{8}$ There are minimal formal employment opportunities and 'conventional rubrics for how to achieve, accumulate and exert influence' cannot be relied upon. ${ }^{9}$ In such contexts, young people make the most of informal networks and economic opportunities - washing cars, hawking, scavenging and recycling. These activities are typically characterized as entrepreneurial survival strategies necessitated by the disorder, unpredictability and 'sheer turbulence' of everyday life. ${ }^{10}$ Here, we shift the focus towards young people who collect waste (plastic bags) to make things (footballs), not out of economic necessity or because there is a profit to be had, ${ }^{11}$ but for their own enjoyment. And because plastic-bag footballs work. We set the scene through three frames: a policy bundle, a photographic expedition and a fundraising campaign.

\section{A policy bundle}

In mainland Tanzania, a ban on plastic bags between 30 and 65 microns thick was instituted under the Prohibition of Plastic Bags Regulations, 2006 due to environmental concerns. Amendments in 2011 extended the ban to all plastic bags and introduced jail sentences for violators. By October 2012, these regulations were relaxed due to negative impacts on the cut-flower sector, ${ }^{12}$ although in 2016 the Vice President's Office again announced that a total ban would be in place from January 2017. ${ }^{13}$ Zanzibar has adopted a stricter approach. ${ }^{14}$ In 2012, the Zanzibari Government issued a total ban on 'manufacturing, distributing, selling or using all kinds of plastic bags' due to concerns about unsightly pollution, given the islands' economically significant tourism industry. ${ }^{15}$ Plastic bags are routinely confiscated when travellers arrive in Zanzibar; hundreds of plastic bag importers and vendors have been arrested. ${ }^{16}$ Meanwhile the East African Legislative Assembly's East African Community Plastic Control Bill, 2012 prohibited the sale, use, manufacture and import of polyethylene materials throughout the region to 'sustain and protect human and animal lives'. Upon learning of these plastic-bag bans, our first thoughts were not of the environment, human health, wildlife or tourism, but of football and youth. We wanted to document the practice of making plastic-bag footballs, before the bags disappeared.

\section{A photographic expedition and a fundraising campaign}

In 2009, Belgian photographer Jessica Hilltout photographed locally made footballs in ten African countries. In a subsequent National Geographic article, ${ }^{17}$ Hilltout described plasticbag footballs as 'ingenious little jewels'. She proclaimed, 'It's easy to look at a tattered ball and feel sadness. My aim was to make you look at the ball and feel uplifted' ${ }^{18}$ Notwithstanding her admiration for plastic-bag footballs, Hilltout sourced formally manufactured football equipment for the people she had met to 'enable them to keep playing the game they love'. ${ }^{19}$ 
Plastic-bag footballs also feature on the World Vision website, alongside an invitation to donate \$16 for two soccer balls. An accompanying clip proclaims:

The world's children have a passion for soccer, but many kids living in poverty have never played with a real soccer ball. They play with balls made of old rags or corn husks. This boy uses plastic bags. By donating new or gently used soccer balls you can bring joy to a child or maybe an entire village. (Emphasis added) ${ }^{20}$

In both cases, plastic-bag footballs appear as symbols of material deprivation - quaint and inventive but ultimately inferior. Used only as a last resort. Such pitiful/pitying characterizations move swiftly, and uncritically, from an understanding of plastic bags as abject waste, to plastic-bag footballs as tainted technology. They are blind to vernacular 'relatings' between humans and discarded materials that are co-constituted, and evolve. ${ }^{21}$ Moreover, pity narratives diminish the practices and technologies of young plastic-bagfootball makers and players. They create a 'colonial situation', symptomatic of a broader problem with the subordinate positioning of Majority World knowledges and practices. ${ }^{22}$

This article draws together more-than-human and postcolonial theorizing to offer an alternate lens on this practice, and to make sense of plastic-bag footballs - socially and materially amidst ecological crises and the seemingly unmanageable excess of incessant materials. Continued access to abundant resources and materials, especially those that depend upon fossil fuels for their manufacture and/or transport, cannot be assumed over the coming decades. Any possibility of avoiding catastrophic climate change scenarios depends upon voluntarily leaving many resources unused. ${ }^{23}$ Those of us who live in the Minority World ${ }^{24}$ need to learn to consume less, especially petrochemical-based products such as plastic. Beyond raw reductions in consumption, however, plastics will linger, and humans will have to learn to live with and extend relations of care towards troublesome materials that accumulate in landfills and waterways, their slowly unbinding molecular bonds leaching toxins that accumulate at the cellular scale within organic lifeforms. ${ }^{25}$ Plastic-bag footballs tell us something about how both these tasks - reducing consumption and living with care among incessantly troublesome materials - might be done.

\section{Making with waste: a more-than-human perspective}

Waste is often characterized as controllable - it is subject to categorization by humans: measured, managed, disposed of, treated and governed. ${ }^{26}$ Efforts to ban plastic bags in Tanzania, and elsewhere, exemplify this desire. Our approach to plastic-bag waste is informed instead by recent debates across cultural geography, anthropology and science and technology studies on the affordances and capacities of nonhumans. More-than-human approaches refuse to treat 'the human' as 'the privileged if not the only actor of consequence'. ${ }^{27}$ Acknowledged are co-constitutions of humans with diverse and evolving networks (or assemblages) of nonhumans. ${ }^{28}$

Scholars working in Africa have provided informative insights into the social lives of materials and their implications for cultural identities - for instance, Pfaff on mobile phones in Dar es Salaam ${ }^{29}$ and Meier on domestic architectures and interior design along the Swahili coast. $^{30}$ They have also explored local understandings of, and engagements with, the nonhuman (see McGregor on crocodiles in Zimbabwe), ${ }^{31}$ and the political agency of nonhumans. With regards to the latter, Mitchell placed mosquitoes, Plasmodium falciparum, ammonium nitrate, dams and war machines at the front and centre of Egypt's political history. ${ }^{32}$ To our knowledge, a more-than-human lens has not yet been turned to studies of 
waste in Africa, with existing research being focused on solid waste management systems and informal labour networks, and framed around political ecology and environmental justice perspectives. $^{33}$

More-than-human perspectives prompt a different approach to waste. Gay Hawkins has critiqued the singularity of scientific knowledges that frame the plastic bag as 'a bad object'. ${ }^{34}$ For Hawkins, the moral imperative to do away with plastic bags obscures the diverse encounters humans have with them, and their capacity to evoke a complex range of emotions: embarrassment, guilt, regret and disgust, but also appreciation for their convenience. Plastic bags, then, are active participants in socio-political assemblages. While humans do things with and to plastic bags, this does not render the bags subordinate.

Widely influential in such discussions has been Bennett's vital materialism and conceptualization of 'thing-power' - the 'curious ability of inanimate things to animate, to act, to produce effects dramatic and subtle'. ${ }^{35}$ Meanwhile, strands of actor-network theory insist that agency be attributed to associations of humans and nonhumans, rather than being identified as resident in the 'intrinsic qualities' of an assemblage's component parts. ${ }^{36}$ We seek to transcend the oppositional tendencies of this debate, focusing on plastic-bag footballs as vernacular cultural geographic accomplishments, whereby the incessant materiality of component materials makes particular in situ associations of humans and nonhumans (in our case, policies, young men, wind, sand, water) possible.

Our perspective also draws upon more-than-human accounts of cultural geographies of making, remaking, repair and reuse, which stand in stark contrast to normative ideas that 'makers' impose a pre-determined form upon 'neutral and pliable, inanimate' matter. ${ }^{37}$ We draw upon Tim Ingold's reconceptualization of making as a process in which materials play a role. ${ }^{38}$ People who make things (whether carpenters, cooks or plastic-bag-football makers) are intervening in the 'force and flows' of materials in an 'ongoing generative movement'; they are attentive and responsive to materials, they compromise and negotiate with them. ${ }^{39}$ Ingold has also stressed the incompleteness of making. The things people make are only ever temporary 'gatherings of materials in movement' ${ }^{40}$

On this point, our interpretation engages with de Laet and Mol's description of fluid technologies. ${ }^{41}$ Exemplified in the Zimbabwe Bush Pump (a hand water pump), a fluid technology 'isn't too rigorously bounded, [it] doesn't impose itself but tries to serve, [it] is adaptable, flexible and responsive' ${ }^{42}$ Fluid technologies are mutable - they change to adapt to local circumstances but retain their fundamental character. ${ }^{43}$ They are stronger and more reliable than technologies that are 'firm' because they are characterized by 'many grades and shades of 'working'. ${ }^{44}$ They are perpetually in-the-making and their fluidity is not accidental. Via plastic-bag footballs we make a case for the broader relevance of fluid technologies - as an antidote to the 'frenetic and indiscriminate consumption of essentially disposable products' $^{45}$ that characterizes everyday life, especially in the Minority World. Doing so requires a willingness to follow postcolonial scholars' calls to 'think from the South'. ${ }^{46}$ And, in iterative fashion, this requires thinking with, rather than always against, materials such as plastic that linger as waste.

\section{Countering neocolonial positionings of Majority World knowledges}

The exposition of plastic-bag footballs put forward in this paper seeks to counter neocolonial framings that cast vernacular, Majority World technologies and adaptations as inferior, as merely ways of making do. Our approach to postcolonial theory is inspired by key thinkers 
within the 'modernity/coloniality program' who wish to extend Chakrabarty's call to provincialize Europe, ${ }^{47}$ and by relatively recent work emerging from postcolonial African cities. $^{48}$

These bodies of work challenge modernist thinking, which has elevated Minority World knowledges to the status of rational science and philosophy, vis-à-vis the 'traditional knowledges' and 'folk wisdoms' of the Majority World. ${ }^{49}$ Our thinking here is also informed by Blaser's discussion of the pluriverse, of co-existing multiple ontologies, as a challenge to the 'impoverishment implied by universalism'. ${ }^{50}$ Postcolonial scholars have been concerned to de-objectify Majority World knowledges, instead recognizing them as subjects capable of contributing on equal terms. They have raised powerful challenges to the framing of Africa as 'a residual entity', asserting that studies from/on that continent do not merely contribute to knowledge of Africa, but to 'knowledge of the world' and 'of the human condition in general' ${ }^{51}$ In this vein, Thieme observed that her ethnography of young people in a Nairobi 'slum' provides opportunities to understand 'conditions of uncertainty for young people across geographies' (emphasis added) - for instance, those affected by austerity measures and precarious employment in the Minority World. ${ }^{52}$ Meanwhile Myers articulated a series of 'thought experiments' that bypassed and reversed expected comparisons of cities in the Majority World with those in the Minority World, challenging the usual flow of intellectual authority. ${ }^{53}$ Following Robinson's call for geographers to learn from and engage with 'understandings generated in other places', ${ }^{54}$ Myers asked how insights from research on African urbanism (specifically from Nairobi and Cape Town) could be used to overcome urban divides in Hartford, Connecticut.

Unpicking this subject/object binary (between Majority and Minority World knowledges), alongside the human/non-human binary (discussed in the previous section), provides a powerful opportunity to think differently about devalued materials, expertise, resourcefulness, agency, and waste. ${ }^{55}$ Existing efforts to combine postcolonial and morethan-human theoretical perspectives have been mutually productive. More-than-human theorizing expands the remit of traditional postcolonial geography by emphasizing the political significance of diverse nonhumans. It compels attentiveness to the things that happen beyond human intention and design. ${ }^{56}$ A postcolonial perspective, for its part, pushes more-than-human theorists to resist the 'flat ontology' of assemblage thinking by foregrounding power dynamics - particularly those between the west and its former colonies. $^{57}$ The task, then, is not merely about making sense of other ontologies in the places where they exist. Instead, we need to rethink globally dominant analytical concepts and ways of living (including Minority World lifestyles of mass consumption and disposability), through other, marginalized, ontologies. In the context of this paper, this requires an openness to acknowledge the capacities of our most maligned waste materials, and to 'write the world from Africa or to write Africa into the world'. ${ }^{58}$

\section{On plastic-bag footballs and the young men who make them}

In the wake of legislation banning plastic bags in mainland Tanzania and Zanzibar, two of the authors left Australia in August 2012 expecting to encounter plastic-bag-football making as a practice in decline. Our goal is to document this practice, before the bags disappeared.

Upon disembarking at Zanzibar's main port we encountered a large billboard featuring the official crest of the Revolutionary Government of Zanzibar and a drawing of plastic bags under a large red cross, alongside the text: 'The use of plastic bags is strictly prohibited in Zanzibar'. Despite such strong and visible proclamations, we found that the plastic-bag bans 
had been minimally successful. Plastic bags were still readily available in mainland Tanzania and only slightly less so in Zanzibar. And plastic-bag-football making was an ongoing practice.

We asked young men who make and use plastic-bag footballs to participate in group discussions. Three such groups formed, involving 18 men aged from their late teens to late 30s: two in Dar es Salaam, Tanzania's commercial capital and most populous city, and one in Uroa, a small fishing seaweed farming and tourist village on the East Coast of Zanzibar's main island, Unguja. Dar es Salaam, for its part, is a sprawling, vibrant and globalizing metropolis of around four to five million inhabitants. ${ }^{59}$ It is characterized by immense social, cultural and economic diversity ${ }^{60}$ and stark class divides.

In Dar es Salaam, one of our group discussions took place in the now middle-class Sinza District (where Paul grew up). The area has gentrified considerably due to its proximity to the University of Dar es Salaam and Tanzania's largest shopping mall, Mlimani City. Our other group discussion in Dar es Salaam was held in a comparatively poor neighbourhood, Tandika. Sinza residents were our first point of contact, largely due to Paul's existing relationships. These men were older (than those in Tandika and Uroa), and no longer played football regularly. They reminisced upon their youthful experiences and crucially were able to introduce us to the young men in Tandika. The latter were active plastic-bag-football makers and players at the time of the research. While this practice remains common, such introductions were necessary given the labyrinthine character of Dar es Salaam's neighbourhoods, where unpaved backstreets are difficult to navigate and, to quote a famous song, quite literally have no names. In Uroa, no such introductions were required. We spontaneously came across a group of young men weaving a plastic-bag football along the beachfront, no more than 20 metres from our accommodation.

Paul, a Tanzanian male then in his late-30s, led the discussions in Kiswahili. In Tanzania, football is a masculinized sport, so Natascha (a white, female academic) did not participate directly in the discussions. The men were asked to describe practices of making and playing with plastic-bag footballs, and the implications of the plastic-bag bans. They were also asked to compare experiences of playing with plastic-bag footballs and store-bought counterparts. In due course, Paul was invited to kick the footballs around with the young men. Play enabled visceral experience of the material affordances of plastic-bag footballs and engagement with the surrounding landscapes.

\section{Of scavenging for plastic bags}

At the time of our visit, young men in Dar es Salaam could easily source plastic bags for football-making; the ban had been loosely enforced on the mainland. Those in Uroa, Zanzibar, had seen less plastic bag litter since the ban; it was harder to find enough plastic bags to make a football than before. Sadiq used to collect plastic bags on the beach while walking to and from the madrasa (religious school); the ban forced him to walk longer distances to landfill sites. We were later taken to visit one of these (Figure 1). It was open and readily accessible. Plastic bags were not contained and could easily float, fly or be taken away.

Scavenging for plastic bags on streets and beaches, and in rubbish bins and landfills, was described as routine. The young men's stories revealed how the material recalcitrance of plastic bags (typically framed in negative terms in environmental campaigns) creates 
opportunities for reclassification. The refusal of plastic bags to break down, paired with their lightness - and thus capacity to evade neat and permanent disposal - are precisely what makes them available to football-makers. The young men we spoke to enact, in their everyday lives, an understanding of plastic bags that contravenes the prevailing negative category of 'waste'. ${ }^{61}$ They are responsive to plastic bags, are able to acknowledge their mutable affordances, and have the skill to imagine and enact new relations with them. These young football-makers are engaged in 'the arts of transience': they show an ability to 'work with the future potentialities in things' ${ }^{62}$ Crucially, they do not treat plastic bags as complete objects. Instead, they view them as materials that can be enrolled to make new things (footballs) which are, in turn, unstable and temporary gatherings of materials in which the potential for 'further making, growth and transformation' is ever present. ${ }^{63}$

\section{Making plastic-bag footballs}

The football-making process was described in detail by Gerard (in Tandika):

First, you take something like socks . . . you pour in a little sand and you tie a knot. Then, you take plastic bags, you tie them around the outside . . . until it has reached a certain size ... a size which you know this can be a football ... You tie the last plastic bag around the outside, then you look for nylon string, you put it across the middle like that, you tie a knot on top ... Y You cut [more] string, you tie it across again, it becomes like a criss-cross. Then you look for [more] string and start to weave ... little by little ... you can't weave leaving big gaps [between the nylon threads] . . . or it will unravel.

It takes between a few hours and one day to make a football, depending upon its complexity, size and design. Football-makers incorporate a range of other materials: mattress foam, fabric, rags, socks, sand, nylon strings, bits of rice sacks, sometimes even leather. If a heavier football is desired, it is filled with sand, or for a lighter variety with mattress foam. Like the Zimbabwe Bush Pump, the plastic-bag football is variable. Uniformity is not required; moreover, it is undesirable because local playing conditions are never quite the same. As fluid technologies, these footballs change their shape and characteristics as needed, but retain a coherent identity as plastic-bag footballs.

The young men deliberately sidestepped questions about the precise number of plastic bags needed to make a football. Their reticence to specify a 'recipe' reveals the making process as one in which the practitioner brings together diverse materials 'in the anticipation of what might emerge'. ${ }^{64}$ Rather than imposing a pre-determined form, the practitioner is attentive and responsive to materials, following 'from one direction marker to the next'. ${ }^{65}$ An exact number cannot be generalized: it depends upon the size of the football desired; the size, thickness and texture of the plastic bags being used; and the practitioner's sense of when enough is enough. This is a process of 'individuation', in which form is emergent, not preordained. ${ }^{66}$ Once 'enough' plastic bags have been assembled the outer layer is bound, usually with nylon strings (Figure 2). Hamad (Sinza) uses pure white nylon strings shredded from chalk sacks to make the outer layer of his footballs attractive. Others cover the nylon string layer with fabric or leather - offcuts from sofa making (another informal roadside making practice in Tanzania) are ideal due to their strength. This final covering protects the nylon strings (which can unravel if cut by sharp rocks or toenails during play) and contributes aesthetic appeal via a decorative surface. We were shown one cloth-covered football in Tandika that the maker had designed to resemble the official 2010 South African World Cup football (Figure 3). 
After a month or so of use, most plastic-bag footballs require repair work. That footballmakers invest time in maintenance provides evidence of value. These plastic bags are not valueless 'waste': they are the key component of a football that is worth repairing. And through continual repair, relations of care are extended towards materials otherwise discarded, rendered abject. ${ }^{67}$

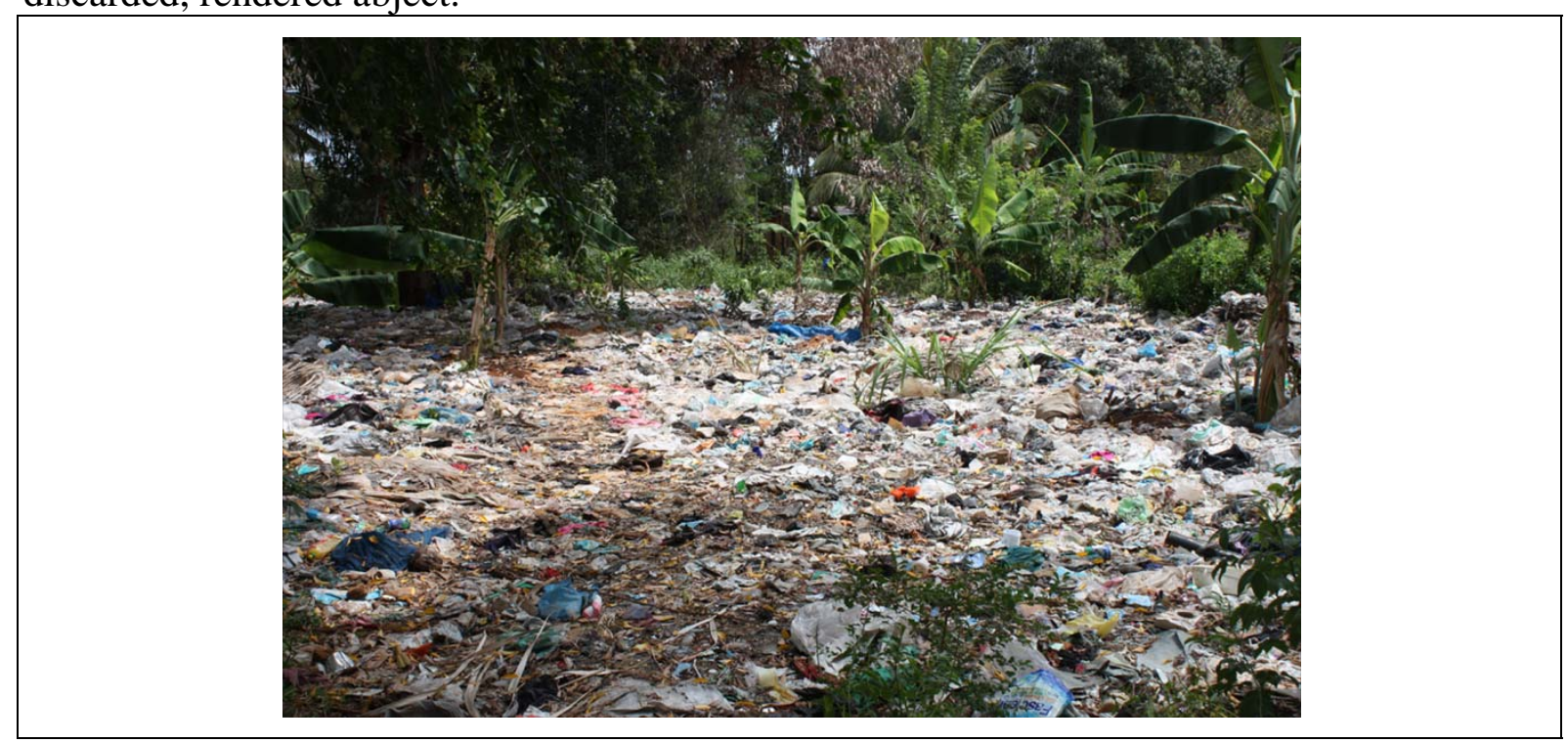

Figure 1. A plastic-bag landfill site, Zanzibar. Photo credit: Natascha Klocker.

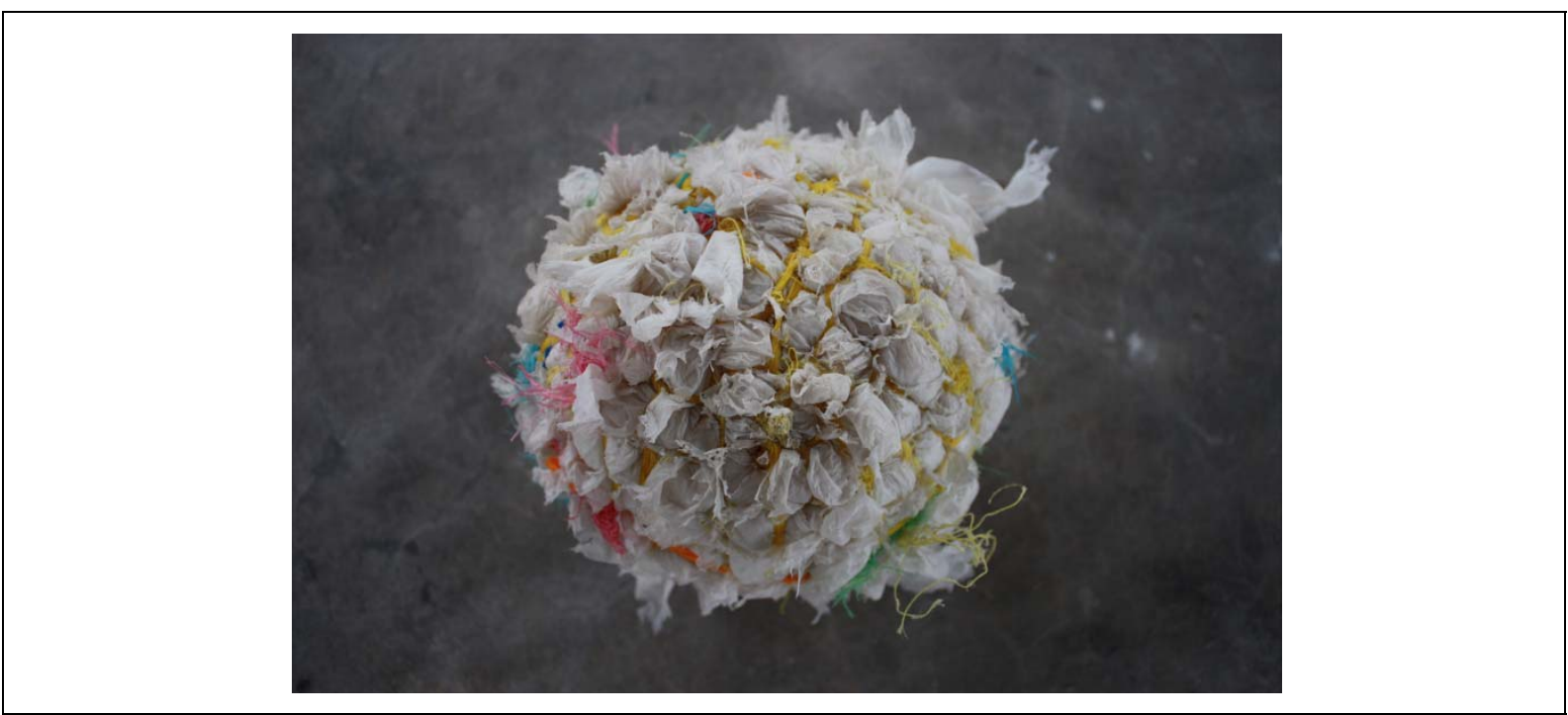

Figure 2. A plastic-bag football, Uroa Bay, Zanzibar. Photo credit: Paul Mbenna.

Not all plastic-bag footballs are equal. Among groups of football-playing young men there is usually one highly skilled craftsman whose footballs are sought after: they are more robust and play better. The best feeling footballs were described as being quite light, but still hard and substantial. As Gerard (Tandika) observed, 'the difficulty is it shouldn't be heavy, it's hard, [but] . . . if you kick it, or if the keeper is holding it like this, he should know yes, I'm really holding a football here'.

Plastic-bag football design has evolved over time, with new innovations affecting function and aesthetics: 


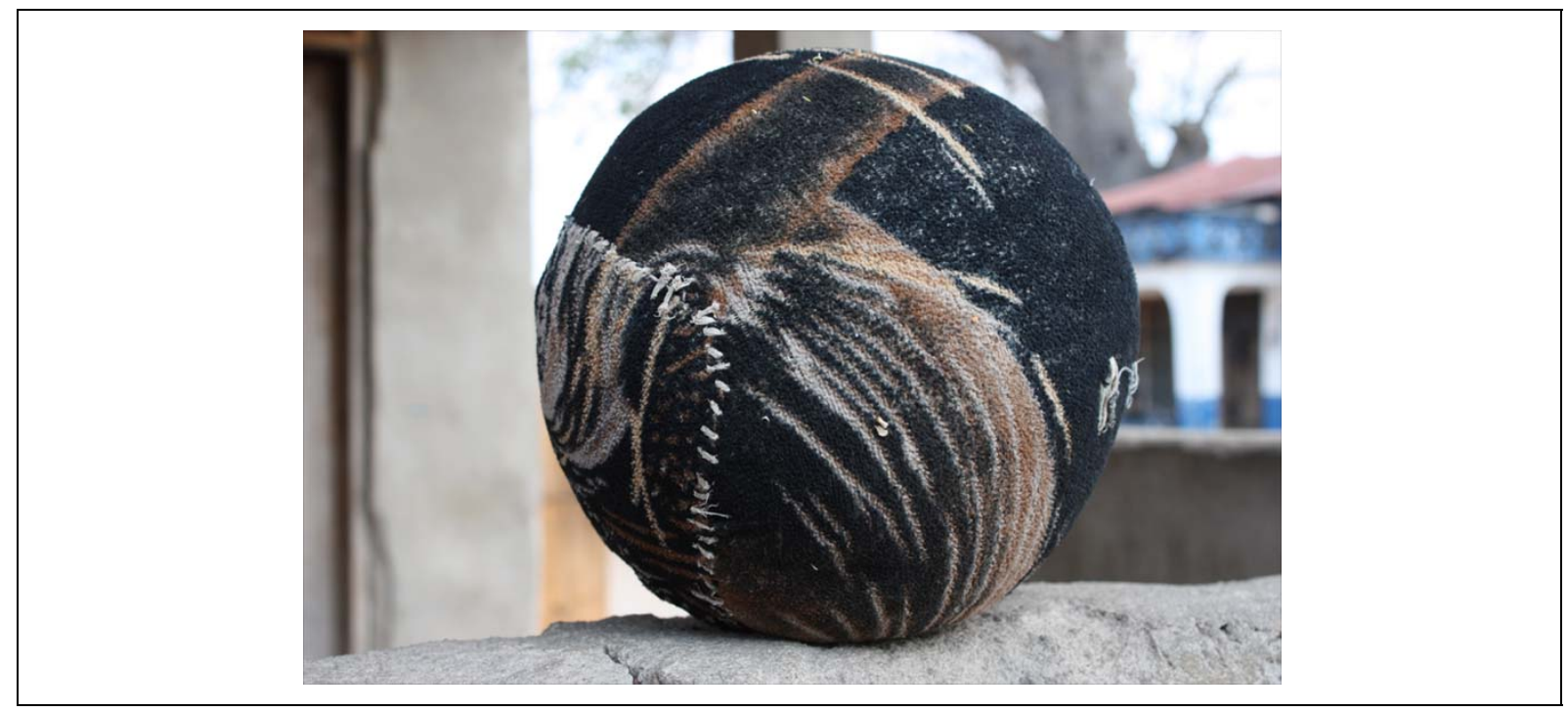

Figure 3. A cloth-covered plastic-bag football, Tandika, Dar es Salaam. Photo credit: Paul Mbenna.

[T]hey used to make the footballs heavy. Afterwards, they started to improve them, they became light . . . they put foam inside . . . they put leather . . . they put fabrics . . . at least it should look good, contemporary. (Hamad, Sinza)

The plastic-bag football is a 'changeable object'; its makers are continually restyling, improving and experimenting. ${ }^{68}$ Some skilled football-makers, like Gerard, are able to make extra footballs and sell them, for 200 Tanzanian Shillings (Tsh.) in Uroa, or up to Tsh. 2000 in Dar es Salaam (around US9c and US89c, July 2017).

\section{Playing with plastic-bag footballs, with care}

Plastic-bag-football makers impose intricate codes of conduct and care in response to plastic materiality, to minimize wear and tear. The young men all play barefoot, protecting the footballs from damage. Players who kick with their big toes, instead of the tops or sides of their feet, are roundly criticized. Such complaints are not about playing ability, but the risk posed to the football. Big toes (and toenails) damage plastic-bag footballs when caught between the weave, causing the nylon strings to unravel, or by cutting the plastic bags themselves. Players who kick with their big toes are warned:

I definitely had to give a warning . . . 'My friends, any person . . . who plays with it poorly [so] it unravels, must bear the cost' ... . Or you will hear a person saying, 'He has a habit of kicking with his big toe' . . . we will tell him unequivocally that we don't like that habit. (Hamad, Sinza)

Paul recalled how the neighbourhood football-maker of his youth would inspect the length of players' toenails before permitting them to play. Plastic materiality evokes specific relations of care towards temporarily assembled objects. And indeed, when played with care plasticbag footballs can last for several years. ${ }^{69}$

Plastic-bag footballs hold many advantages over the store-bought variety. Leather footballs are painful: 'If you're used to playing barefoot . . . if you kick a leather football without clenching your foot, you will get hurt. But if you play with a plastic-bag football you'll be fine' (Hamad, Sinza). Plastic-bag footballs are gentle on feet, particularly after they have 
been worn in. Players' feet, in turn, respond to plastic-bag footballs. As noted by Mohammed (Sinza), a plastic-bag football:

has its own joy ... when you play barefoot, the sun is shining down, your feet themselves start to mature ... once you've taken off your shoes, you don't need anything else, even socks ... you can just play.

Plastic-bag footballs are also ideal for learning ball control, particularly for young children as a string can be tied to the football for juggling practice. ${ }^{70}$ 'Lime' (ndimu) is a colloquial term for plastic-bag footballs (used because, like the fruit, they are small, dense and firm to the touch). Mohammed (Sinza) commented, 'with the lime, you have a lot of control and a lot of talents . . . come from playing with plastic-bag footballs'. Gerard (Tandika) described leather footballs as a real 'exam' because they are challenging to control in the places where these young men play.

\section{Designing for site}

Despite being relatively light, plastic-bag footballs are heavier and move with less pace than store-bought ones, so matches are less frequently interrupted by the ball being kicked out of the pitch. The footballs also move predictably, because plastic bags are not bouncy. Such attributes are ideally suited to the material surroundings where these young men play: on the beaches of Uroa and on unpaved streets and small vacant lots in Dar es Salaam. The design of the footballs can be modified, depending on the local playing surface - each version 'contains a variant of its environment'. ${ }^{71}$ Because plastic-bag footballs are ideally suited to local playing surfaces, they offer convenience: 'The pitches where people play with leather [footballs] are far away . . . it's better to be here, close to home, and just play' (Linus, Tandika).

Uneven surfaces and cramped playing spaces were described as unsuitable for store-bought footballs, which readily bounce over walls or break neighbours' windows. According to Linus (Tandika), matches played with a store-bought football aren't 'very entertaining', because 'if you just kick it a little, it will go over the wall'. Store-bought footballs do not have 'a good feeling', in Gerard's words. Japher complained, 'you don't [get to] play . . . for more than two kicks . . . before the person in this house [pointing] comes outside because their window is broken'. Store-bought footballs are also difficult to control on Zanzibari beaches. On formal match days, the young men from Uroa sometimes walk long distances to play on a football pitch, but those pitches are also replete with divots:

Here, in Uroa Bay, we like plastic-bag footballs because of the geography, the environment . . . Our pitches have a lot of craters, so it is difficult to control a leather football . . . A plastic-bag football is good for playing on the beach because it has the weight and balance that is needed . . . a lot of young people here . . . wouldn't be very happy to play with leather footballs ... . [they] are very light and move quickly . . . a leather football goes out of the pitch easily. (Sadiq)

Sadiq wove a plastic-bag football during the group discussion. Once it was complete, he demonstrated his football-juggling techniques on the beach. At the same time, Paul and another young man (both competent players) started to juggle a store-bought football we had brought with us. The steadiness of the plastic-bag football was readily observable. While Sadiq did not lose control of the plastic-bag football, the store-bought football repeatedly got away from the other men, forcing them to chase it along the beach. This 'performance in 
place $^{72}$ provided a depth of insight, unattainable through discourse alone, into the 'real toand-fro-ing of subjectivity and environment'. ${ }^{73}$

Store-bought footballs do not suit the environments where these young men play (as shown in Natascha's reflection at the start of this article). They are readily punctured and can only be repaired with store-bought equipment. They can also be irreparably damaged by saltwater when playing on the beach. Plastic-bag footballs were described as reliable and easy to maintain and repair, exemplary fluid technologies. Like the Zimbabwe Bush Pump, being in working order does not require a constant and consistent configuration. ${ }^{74}$ Plastic-bag footballs do not simply break and move into obsolescence, to be thrown away. Instead, they invite further engagement - their plasticity amenable to tinkering and adjustment as part of an ongoing conversation. The making process in which these young men are engaged is perpetually incomplete. Store-bought footballs, in contrast, are sold and treated as complete objects, as a 'fait accompli'. ${ }^{75}$ Plastic-bag footballs are forgiving of 'local patterns of use and abuse'; they move with relative ease from being broken back to working order; they 'incorporate the possibility of their own break-down, ${ }^{76}$ and repair. Such fluidity and responsiveness make plastic-bag footballs useful technologies.

\section{Plastic-bag footballs: an inferior alternative?}

At first glance, plastic-bag footballs appear as a creative response to poverty. To the outsider, they are a way of making do. As the neocolonial logic goes, footballs are crafted out of plastic bags only as a last resort. But attentiveness to socio-material relations reveals that such perceptions are misconstrued. Attributing plastic-bag footballs to poverty overlooks that this practice persists because it works. And it works because those who make and play with these footballs intimately understand how materials respond to their bodies and environments (and vice versa). The young men were unequivocal that they could afford to purchase a football if they wanted to: 'It's not a question of wealth or poverty' (Linus, Tandika). Sadiq (Uroa) was adamant that young men do not enjoy playing with store-bought footballs because they are unsuited to their local environments. Furthermore, the young men's bodies have become habituated to the unique materiality of plastic-bag footballs:

They aren't used to playing with a football that has bounce. If they play with a bouncy football, their control decreases . . . you find they want a plastic-bag football because they can play low [keep the ball close to the ground]. (Hamad, Sinza)

Prior to our arrival in Tanzania in 2012, we expected to find that plastic bags were increasingly scarce (due to the ban) and that young men's opportunities to play football had diminished accordingly. We brought along six high-quality store-bought footballs (three leather, three synthetic) to give to teams if they could no longer play because of the plasticbag ban. Of course, we ultimately found that the practice of making plastic-bag footballs was still thriving. Plastic bags' lingering presence makes them ecological villains, but paradoxically sustains Tanzanian vernacular football-making. ${ }^{77}$ We also learned that if plastic bags disappear entirely in the future (an unlikely scenario over the short- to medium-term), ${ }^{78}$ alternative materials such as banana leaves and scraps of cloth do exist. ${ }^{79}$ Indeed, Paul's father reminded us that he used to make footballs in this way during Tanzania's socialist era. Reluctant to carry our footballs back to Australia, at the end of each group discussion Paul asked the young men if they wanted to keep one. He felt sheepish doing so. The group in Sinza did not play regularly enough to need a football. Those in Tandika politely but firmly declined, noting that the store-bought footballs were not functional in their neighbourhood. In Uroa, the young men took one football, albeit grudgingly. They were at pains to emphasize 
that this store-bought football would be of no practical use in their everyday lives. They would put it aside and might be able to use it one day, if they played in a tournament on a large, manicured pitch. The young men's actions in Tandika and Uroa were powerful. They provoked a postcolonial moment for this research, described by Hall as an occasion for 'theorising . . . differences and samenesses in new ways'. ${ }^{80}$

Unlike other youthful cultural pursuits that readily translate into overt political commentary and/or activism (as shown in discussions of hip hop and rap music in Senegal and Tanzania), ${ }^{81}$ the everyday practice of making and playing with plastic-bag footballs does not appear to be politically motivated. When young men in Uroa scavenge for plastic bags in landfill sites, they are subverting a policy designed to render plastic bags invisible - but this does not seem to be their intent. When asked, they expressed support for Zanzibar's plasticbag ban and they certainly did not intend to explicitly protest against it. Equally, by using plastic-bag footballs, these young men deftly evade chains of labour exploitation associated with multinational corporations who 'employ' young people in other parts of the Majority World to stitch commodity footballs. But again, there was no expressed political intent. For these young men, making plastic-bag footballs is a matter of getting on with everyday life: a means to play. Yet their everyday practice does defy modernizing logics. ${ }^{82}$ Their insights unsettle assumptions about what types of knowledges and technologies are superior.

While making and playing with plastic-bag footballs is part-and-parcel of everyday life, in the moment of our research encounter the young men's disparagement of our store-bought footballs appeared - to us - as a political manoeuvre. They could have politely taken our gifts and put them aside, never to be used. Instead, two separate groups of young men - who had no contact with one another - chose to be defiant, to prove a point. In so doing, they revealed that the power dynamics of the research encounter were not as we had first supposed. The young men were not powerless subjects of plastic-bag bans and our store-bought footballs would not save the day. Instead, the particular socio-material association (of plastic bags, mattress foam, nylon strings, socks, sand, young men and local environments) afforded an opportunity for resistance. Bringing nonhumans into politics in this way requires an understanding that agency is relational, and that politics depends on both material affordances and associations of humans and non-humans acting in concert. ${ }^{83}$ It is only by charting the 'exhaustively related worlds' of plastic-bag-football making and playing that store-bought footballs are 'suddenly made strange' and revealed as deficient, challenging an established social order. $^{84}$ In this case, the challenge was to the hegemony of neocolonial knowledge/power relations that position Majority World practices and technologies as substandard. ${ }^{85}$

\section{Conclusion: fluid technologies for an intractable world?}

More-than-human and postcolonial geographies can inform one another in highly productive ways: by emphasizing the political significance of nonhumans, and by attuning assemblage thinking to questions of power. When combining these perspectives it is possible to 'throw people off their routine readings and decipherings ${ }^{86}$ of marginalized lives and maligned materials. We have brought more-than-human and postcolonial theorizing together to two ends. First, to challenge neocolonial logics that frame Majority World technologies (like plastic-bag footballs) as inferior - in the very contexts in which they are made and used. Contra the prevailing rhetoric, young men who make and play with plastic-bag footballs do not feel deprived. They feel joy, and care for their bespoke-made objects. They do not need pity, or saving. Rather, the young men we spoke to demonstrated an innate attentiveness and embodied knowledge of plastic bags' material affordances, and of their local landscapes. 
They engaged with plastic-bag footballs expertly and deftly, as fluid technologies perpetually incomplete, always in-the-making and functional in diverse states. These young men challenged neocolonial anticipations of what makes a 'good technology' and asserted the value of their knowledges and practices within their own local environments. ${ }^{87}$ To us this resistance appeared an example of the 'steady, grinding efforts' needed 'to hold one's own against [the] overwhelming odds' of pervasive, persistent and demoralizing neocolonial power relationships that seek to undermine the things that marginalized people value, the very things that work in their everyday lives. ${ }^{88}$

Second - and set against the foreboding background of the Anthropocene - a postcolonial more-than-human perspective compels us to use the case of plastic-bag footballs to think outwards from the Majority World. We are impelled to ask: if marginalized Majority World knowledges were to be understood as equal subjects (rather than objects for analysis), what might they say? How might they speak, across geographies, ${ }^{89}$ to Minority World lives and practices? If given due weight, what might they reveal about the types of practices, skills and technologies that are needed to confront the challenges of disposability in all sorts of places? These are important, existential questions that get to the nub of how humans live with materials, and which attempt to intervene in (and reverse) the 'geopolitics of knowledge'. ${ }^{90}$ They challenge us to recognize that socio-material relations practised in the Majority World are not just useful there, in specific local places (such as Zanzibari beaches). Instead, fluid technologies - and the people who make them and use them - provide important insights for different and less wasteful socio-material relations in the Minority World. Plastic-bag footballs are more than curios through which academics can make sense of Majority World lives and knowledges (as though the latter, too, were objects - lacking in agency and wider relevance). Moving away from this particular subject-object binary requires genuine and open consideration of 'other ontologies as plausible and viable alternatives to the modern one'. ${ }^{91}$ Socio-material relations in diverse parts of the Majority World (of which plastic-bag footballs are but one example) can thus be instructive for resource-intensive lifestyles in the Minority World.

It is important to note here that the plastic-bag-football makers involved in our research were not motivated by environmental concern, but by a desire to play football. While they were clearly recycling (or upcycling) waste, they did not frame their actions in this way. Yet, as acknowledged by a large and growing body of cultural geographic research, many environmentally beneficial actions are undertaken inadvertently, rather than out of an intentional desire to be 'green'. ${ }^{92}$ Such inadvertent environmentalisms can be more broadly instructive if they are brought to light and better understood. Diverse ways of living with materials already exist. But they are often overlooked or downplayed as idiosyncratic of poverty, of limited broader relevance. As plastic-bag footballs demonstrate, opportunities to think through different ways of living with materials arise in unexpected places. Majority World examples of vernacular making - with excess, lingering materials - provide openings for marginalized knowledges and socio-material relations to be taken seriously, as humans grapple with the urgency of establishing new ways of living in the Anthropocene. Alternative ways of living with materials have also been revealed through engagement with migrant populations living within the borders of affluent countries - and who often enact a range of (inadvertent) environmentalisms, characterized by frugal and careful resource use. ${ }^{93}$

Taking greater stock of Majority World knowledges and practices, in all of the places where they take shape, can provide important insights for how to make things and live with materials differently. An implication is renewed focus on the knowledges and skills of people 
who make things with care, using materials otherwise rendered waste, in unlikely or overlooked circumstances. This offers a constructive response to the mess of affluent overconsumption, and is premonitory for forthcoming lives and landscapes in the Anthropocene, awash with detritus and polluting substances. Plastic-bag footballs are environmentally beneficial for an obvious reason: they are recycled, made from waste. Here we have been more concerned with their fluidity, and the relations of use, care and play evoked. Working responsively with materials, with care - as plastic-bag-football makers do - enables technologies to live longer lives. Our key argument is that objects that are always-in-themaking, and functional in diverse states, are relevant beyond places typically pigeon-holed by poverty. The utility of fluid technologies is not limited to the Majority World, where (it is assumed) people cannot afford to buy new stuff when their old stuff breaks. Acknowledging this requires a shift in values, recognition that fluid technologies are not inferior renderings of formally manufactured, sold-as-complete technologies. It also requires a pronounced shift in the ways knowledges are valued across and between the Majority and Minority Worlds. More fluid ways of living with materials undoubtedly reduce aggregate resource consumption and waste. And, in a context of unpredictable and non-linear environmental change - where established ways of life may change abruptly and catastrophically - the ability to work resourcefully, deftly and responsively with incessant materials may yet prove a vital skill for survival. In the case of plastic-bag footballs, these skills also enable young people to simply play.

\section{Acknowledgements}

We wish to acknowledge the three anonymous referees of this paper and Dydia DeLyser who pushed this paper in productive directions. Our thanks also to numerous colleagues who have provided generous and instructive feedback on various drafts of this manuscript: Chantel Carr, Lesley Head, Leah Gibbs, Noel Castree, Catherine Phillips, and Elyse Stanes. Natascha wishes to thank the University of Wollongong Mid-Career Academic Development Program for a writing retreat that provided space and time for the final version of this paper to take shape. We thank Nicole Michielin for research assistance. Our gratitude is also extended to the young men in Uroa Bay and Dar es Salaam who gave generously their time, expertise and craftsmanship.

\section{Funding}

The author(s) received no financial support for the research, authorship, and/or publication of this article.

\section{Notes}

1. M.Liboiron, 'Redefining Pollution and Action: The Matter of Plastics', Journal of Material Culture, 21, 2016, pp. 87110; J.Njeru, 'The Urban Political Ecology of Plastic Bag Waste Problem in Nairobi, Kenya', Geoforum, 37, 2006, pp. 1046-58.

2. C.Gibson, C.Farbotko, N.Gill, L.Head and G.Waitt, Household Sustainability: Challenges and Dilemmas in Everyday Life (Cheltenham: Edward Elgar, 2013).

3. G.Hawkins, The Ethics of Waste: How We Relate to Rubbish (Oxford: Rowman \& Littlefield, 2006), p. 30.

4. H.Ndee, 'Prologue: Sport, Culture and Society in Tanzania from an African Perspective', The International Journal of the History of Sport, 27, 2010, pp. 733-758.

5. D.Ayuku, W.Odero, C.Kaplan, R.de Bruyn and M.de Vries, 'Social Network Analysis for Health and Social Interventions among Kenyan Scavenging Street Children', Health Policy and Planning, 18, 2003, pp. 109-18; A.Baudouin, C.Bjerkli, Y.Habtemariam and ZF.Chekole, 'Between Neglect and Control: Questioning Partnerships and the Integration of Informal Actors in Public Solid Waste Management in Addis Ababa, Ethiopia', African Studies Quarterly, 11, 2010, pp. 29-42.; C.Bjerkli, 'Urban Services and Governance: The Case of Solid Waste Management in Addis Ababa, Ethiopia' (PhD Thesis, Norwegian University of Science and Technology, Trondheim, 2013); G.Rockson, F.Kemausuor, R.Seassey and E.Yanful, 'Activities of Scavengers and Itinerant Buyers in Greater Accra, Ghana’, Habitat International, 39, 2013, pp. 148-55. 
6. A.Honwana, The Time of Youth: Work, Social Change and Politics in Africa (Sterling: Kumarian, 2012).

7. A.Simone, 'Urban Circulation and the Everyday Politics of African Urban Youth: The Case of Douala, Cameroon', International Journal of Urban and Regional Research, 29, 2005, p. 519.

8. T.A.Thieme, 'The Hustle Economy: Informality, Uncertainty and the Geographies of Getting by', Progress in Human Geography. Epub ahead of print 2 February 2017. DOI: 10.1177/0309132517690039.

9. R.Fredericks, 'The Old Man Is Dead': Hip Hop and the Arts of Citizenship of Senegalese Youth', Antipode, 46, 2014, pp. 130-48; E.Moyer, 'Popular Cartographies: Youthful Imaginings of the Global in the Streets of Dar es Salaam, Tanzania', City \& Society, 16, 2004, pp. 117-43; Simone, 'Urban Circulation and the Everyday Politics of African Urban Youth', p. 529; Thieme, 'The Hustle Economy'.

10. F.de Boeck, 'Divining' the City: Rhythm, Amalgamation and Knotting as Forms of 'Urbanity”, Social Dynamics, 41, 2015, pp. 47-58.

11. A.Herod, G.Pickren, A.Rainnie and S.McGrath Champ, 'Global Destruction Networks, Labour and Waste', Journal of Economic Geography, 14, 2014, pp. 421-41.

12. A.Ihucha, 'Ban on Plastic Bags Threatens Tanzania's Cut-Flower Sector', The East African, 2012, $<$ http://www.theeastafrican.co.ke/news/Ban-on-plastic-bags-threatens-Tanzania-cut-flower-sector/-/2558/1521072//a3bh11/-/index.html> (12 June 2013).

13. No author, 'Tanzania: Total Plastics Use Ban Plan by Next Jan Remains - Govt', The Citizen, 2016, $<$ http://allafrica.com/stories/201608190071.html> (22 December 2016).

14. Zanzibar is a semi-autonomous Indian Ocean island territory in a political union with mainland Tanzania (known together as the United Republic of Tanzania).

15. I.Yussuf, 'Tanzania: Battle against Plastic Bags Gains Ground', Tanzania Daily News, 2012, $<$ http://allafrica.com/stories/201203070031.html> (12 June 2013).

16. Yussuf, 'Tanzania’.

17. J.Berlin, 'Joy Is Round', National Geographic, 2, 2013, p. 114.

18. Berlin, 'Joy Is Round', p. 122.

19. Berlin, 'Joy Is Round', p. 119.

20. World Vision, '2 Soccer Balls', <http://www.WorldVision.org/SoccerBalls> (12 July 2017).

21. G.Hawkins, 'The Politics of Bottled Water', Journal of Cultural Economy, 2, 2009, pp. 183-95. See also C.Phillips, 'Revealing Materials: Plastics in Alternative Food Economies', Australian Geographer, 48, 2016, pp. 169-84; E.Stanes and C.Gibson, 'Materials That Linger: An Embodied Geography of Polyester Clothing', Geoforum, 85, 2017, pp. 2736.

22. A.Escobar, 'Worlds and Knowledges Otherwise', Cultural Studies, 21, 2007, pp. 179-210; W.Mignolo, 'Delinking', Cultural Studies, 21, 2007, p. 452; O.Mannoni, Prospero and Caliban: The Psychology of Colonization (London: Methuen, 1956) p. 18.

23. C.McGlade and P.Ekins, 'The Geographical Distribution of Fossil Fuels Unused When Limiting Global Warming to $2^{\circ} \mathrm{C}^{\prime}$, Nature, 517, 2015, pp. 187-90.

24. We adopt the terms 'Minority World' and 'Majority World' rather than Global North/ South, developed/developing, First/Third World, western/non-western to reflect the reality that 'developed world' lifestyles account for the experiences of a minority of the world's population (Punch 2003). We acknowledge that Majority/Minority World are also general categories that cannot fully encompass diverse lives.

25. MP.de la Bellacasa, 'Matters of Care in Technoscience: Assembling Neglected Things', Social Studies of Science, 41, 2011, pp. 85-106; N.Gregson, H.Watkins and M.Calestani, 'Inextinguishable Fibres: Demolition and the Vital Materialisms of Asbestos', Environment and Planning A, 42, 2010, pp. 1065-83; Liboiron, 'Redefining Pollution and Action'.

26. N.Gregson and M.Crang, 'Materiality and Waste: Inorganic Vitality in a Networked World', Environment and Planning A, 42, 2010, pp. 1026-32; Hawkins, The Ethics of Waste.

27. J.Sundberg, 'Decolonizing Posthumanist Geographies', Cultural Geographies, 21, 2014, p. 34; S.Whatmore, 'Materialist Returns: Practising Cultural Geography in and for a More-than-Human World', Cultural Geographies, 13, 2006, pp. 600-9.

28. Sundberg, 'Decolonizing Posthumanist Geographies'; M.Müller, 'Assemblages and Actor-Networks: Rethinking SocioMaterial Power, Politics and Space', Geography Compass, 9, 2015, pp. 27-41.

29. J.Pfaff, 'A Mobile Phone: Mobility, Materiality and Everyday Swahili Trading Practices’, Cultural Geographies, 17, 2010, pp. 341-57.

30. P.Meier, 'Objects on the Edge: Swahili Coast Logics of Display', African Arts, 42, 2009, pp. 8-23.

31. J.McGregor, 'Crocodile Crimes: People versus Wildlife and the Politics of Postcolonial Conservation on Lake Kariba, Zimbabwe’, Geoforum, 36, 2005, pp. 353-69.

32. T.Mitchell, Rule of Experts: Egypt, Techno-Politics, Modernity (Berkeley: University of California Press, 2002).

33. Bjerkli, 'Urban Services and Governance'; Njeru, 'The Urban Political Ecology of Plastic Bag Waste Problem in Nairobi, Kenya'.

34. G.Hawkins, 'More-than-Human Politics: The Case of Plastic Bags', Australian Humanities Review, 46, 2009 , p. 1.

35. J.Bennett, 'The Force of Things: Steps toward an Ecology of Matter', Political Theory, 32, 2004, pp. 347-72.

36. S.Abrahamsson, F.Bertoni, R.Ibáñez Martín and A.Mol, 'Living with Omega-3: New Materialism and Enduring Concerns', Environment and Planning D, 33, 2015, pp. 334-19; Müller, 'Assemblages and Actor-Networks'.

37. D.DeLyser and P.Greenstein, 'The Devotions of Restoration: Materiality, Enthusiasm, and Making Three "Indian Motocycles” Like New', Annals of the Association of American Geographers. Epub ahead of print 2 June 2017. DOI: 10.1080/24694452.2017.1310020; T.Edensor, 'Entangled Agencies, Material Networks and Repair in a Building Assemblage: The Mutable Stone of St Ann's Church, Manchester', Transactions of the Institute of British 
Geographers, 36, 2011, pp. 238-52; C.Carr, 'Maintenance and Repair beyond the Perimeter of the Plant: Linking Industrial Labour and the Home', Transactions of the Institute of British Geographers. Epub ahead of print 15 May 2017. DOI: 10.1111/trans.1183.

38. T.Ingold, 'The Textility of Making', Cambridge Journal of Economics, 34, 2010, pp. 91-102.

39. Ingold, 'The Textility of Making', p. 91; C.Carr and C.Gibson, 'Geographies of Making: Rethinking Materials and Skills for Volatile Futures’, Progress in Human Geography, 40, 2016, pp. 297-315.

40. T.Ingold, 'Towards an Ecology of Materials', Annual Review of Anthropology, 41, 2012, p. 439.

41. M.de Laet and A.Mol, 'The Zimbabwe Bush Pump: Mechanics of a Fluid Technology', Social Studies of Science, 30, 2000, pp. 225-63.

42. de Laet and Mol, 'The Zimbabwe Bush Pump', p. 225.

43. J.Law and A.Mol, 'Situating Technoscience: An Inquiry into Spatialities', Society and Space, 19, 2001, pp. 609-21.

44. de Laet and Mol, 'The Zimbabwe Bush Pump', p. 225.

45. N.Klein, This Changes Everything (London: Penguin, 2014), p. 85.

46. Thieme, 'The Hustle Economy', p. 2.

47. D.Chakrabarty, Provincializing Europe: Postcolonial Thought and Historical Difference (Princeton: Princeton University Press, 2000); M.Dabashi, Can Non-Europeans Think? (London: Zed Books, 2015); Escobar, 'Worlds and Knowledges Otherwise’; Mignolo, 'Delinking', p. 452; A.Quijano, 'Coloniality and Modernity/Rationality', Cultural Studies, 21, 2007, pp. 168-78.

48. A.Mbembe and S.Nuttall, 'Writing the World from an African Metropolis', Public Culture, 16, 2004, pp. 347-62; G.Myers, 'From Expected to Unexpected Comparisons: Changing the Flow of Ideas about Cities in a Postcolonial Urban World', Singapore Journal of Tropical Geography, 35, 2014, pp. 104-18; Thieme, 'The Hustle Economy'.

49. Escobar, 'Worlds and Knowledges Otherwise'; M.Blaser, 'Ontological Conflicts and the Stories of Peoples in Spite of Europe: Towards a Conversation on Political Ontology', Current Anthropology, 54, 2013, pp. 547-68; M.Mawere, Culture, Indigenous Knowledge and Development in Africa: Reviving Interconnections for Sustainable Development (Cameroon: Langaa, 2014).

50. Blaser, 'Ontological Conflicts and the Stories of Peoples in Spite of Europe'.

51. Mbembe and Nuttall, 'Writing the World from an African Metropolis', p. 351.

52. Thieme, 'The Hustle Economy', p. 2.

53. Myers, 'From Expected to Unexpected Comparisons'.

54. J.Robinson, 'Provincializing Geography: Tactics and Pitfalls', Singapore Journal of Tropical Geography, 24, 2003, p. 274.

55. D.MacKinnon and KD.Derickson, 'From Resilience to Resourcefulness: A Critique of Resilience Policy and Activism', Progress in Human Geography, 37, 2013, pp. 253-70; DeLyser and Greenstein, 'The Devotions of Restoration'.

56. Mitchell, Rule of Experts; A.Mol, 'Ontological Politics: A Word and Some Questions', The Sociological Review, 47, 1999, pp. 74-89.

57. M.Jackson, 'Composing Postcolonial Geographies: Postconstructivism, Ecology and Overcoming Ontologies of Critique', Singapore Journal of Tropical Geography, 35, 2014, pp. 72-87; A.Saldanha, 'Assemblage, Materiality, Race, Capital', Dialogues in Human Geography, 2, 2012, pp. 194-7; Sundberg, 'Decolonizing Posthumanist Geographies'.

58. Mbembe and Nuttall, 'Writing the World from an African Metropolis', p. 348.

59. J.Boyle, 'Dar es Salaam: Africa's Next Megacity?' BBC News, 2012, <http://www.bbc.com/news/ magazine-18655647> (11 July 2017); S.Sturgis, 'The Bright Future of Dar es Salaam, an Unlikely African Megacity', CityLab, 2015, <https://www.citylab.com/design/2015/02/the-bright-future-of-dar-es-salaam-an-unlikely-africanmegacity/385801/> (11 July 2017).

60. J.Brennan, A.Burton and Y.Lawi, Dar es Salaam: Histories from an emerging African metropolis (Dar es Salaam: Mkuki na Nyota Publishers, 2007).

61. cf. N.Gregson and M.Crang, 'From Waste to Resource: The Trade in Wastes and Global Recycling Economies', Annual Review of Environmental Resources, 40, 2015, pp. 151-76.

62. N.Gregson, M.Crang, F.Ahamed, N.Akhter and R.Ferdous, 'Following Things of Rubbish Value: End-of-Life Ships, “Chock-Chocky” Furniture and the Bangladeshi Middle Class Consumer', Geoforum, 41, 2010, pp. 846-54, esp. p. 853.

63. Ingold, 'Towards an Ecology of Materials', p. 435.

64. Ingold, 'The Textility of Making', p. 94.

65. Ingold, 'The Textility of Making', p. 97.

66. Ingold, ‘Towards an Ecology of Materials', p. 433.

67. de la Bellacasa, 'Matters of Care in Technoscience'.

68. de Laet and Mol, 'The Zimbabwe Bush Pump'.

69. Ndee, 'Prologue'.

70. Juggling helps to improve players' ball control skills. It involves keeping the football aloft for as long as possible using the feet (and other body parts, excluding hands).

71. de Laet and Mol, 'The Zimbabwe Bush Pump', p. 252.

72. H.Verran and M.Christie, 'Using/Designing Digital Technologies of Representation in Aboriginal Australian Knowledge Practices', Human Technology, 3, 2007, p. 224.

73. A.Saldanha, 'Trance and Visibility at Dawn: Racial Dynamics in Goa's Rave Scene', Social \& Cultural Geography, 6, 2005, p. 709.

74. de Laet and Mol, ‘The Zimbabwe Bush Pump’.

75. Ingold, 'The Textility of Making', p. 96.

76. de Laet and Mol, 'The Zimbabwe Bush Pump', pp. 240, 252. 
77. cf. Gregson and Crang, 'Materiality and Waste'; Stanes and Gibson, 'Materials That Linger'.

78. Paul returned to Tanzania in 2016 to visit family. While no further recorded group discussions were conducted, he was able to confirm that plastic bag waste remains pervasive, and that plastic-bag footballs are still in use.

79. Ndee, 'Prologue'.

80. S.Hall, 'When Was the "Post-Colonial”? Thinking at the Limit', in I.Chambers and L.Curtis (eds), The Post-Colonial Question: Common Skies, Divided Horizons (London: Routledge, 1996), p. 293.

81. Fredericks, 'The Old Man Is Dead'; Moyer, 'Popular Cartographies'.

82. E.Fox Tree, 'Global Linguistics, Mayan Languages, and the Cultivation of Autonomy', in N.Blaser, R.Da Costa, D.McGregor and W.Coleman (eds), Indigenous Peoples and Autonomy: Insights for a Global Age (Vancouver: University of British Columbia Press, 2010), pp. 80-106.

83. J.Bennett, Vibrant Matter: A Political Ecology of Things (Durham: Duke University Press, 2010); Abrahamsson et al., 'Living with Omega-3'; J.Sundberg, 'Diabolical Caminos in the Desert and Cat Fights on the Río: A Posthumanist Political Ecology of Boundary Enforcement in the United States-Mexico Borderlands', Annals of the Association of American Geographers, 101, 2011, pp. 318-36; Müller, 'Assemblages and Actor-Networks'.

84. Verran and Christie, 'Using/Designing Digital Technologies of Representation in Aboriginal Australian Knowledge Practices'.

85. Mawere, Culture, Indigenous Knowledge and Development in Africa.

86. Mbembe and Nuttall, 'Writing the World from an African Metropolis', p. 352.

87. Hall, 'When Was the "Post-Colonial”? Thinking at the Limit'; Mawere, Culture, Indigenous Knowledge and Development in Africa.

88. J.Scott, Weapons of the Weak: Everyday Forms of Peasant Resistance (New Haven: Yale University Press 1985), p. 350.

89. Thieme, 'The Hustle Economy', p. 2.

90. W.Mignolo, 'Foreword', in Dabashi, Can Non-Europeans Think?, p. xii; Myers, 'From Expected to Unexpected Comparisons'.

91. Blaser, 'Ontological Conflicts and the Stories of Peoples in Spite of Europe', p. 556.

92. R.Hitchings, R.Collins and R.Day, 'Inadvertent Environmentalism and the Action-Value Opportunity: Reflections from Studies at Both Ends of the Generational Spectrum', Local Environment, 20, 2015, pp. 369-85.

93. E.Carter, B.Silva and G.Guzmán, 'Migration, Acculturation, and Environmental Values: The Case of Mexican Immigrants in Central Iowa', Annals of the Association of American Geographers, 103, 2012, pp. 129-47; C.Maller and Y.Strengers, 'The Global Migration of Everyday Life: Investigating the Practice Memories of Australian Migrants', Geoforum, 44, 2013, pp. 243-252; N.Klocker and L.Head, 'Diversifying Ethnicity in Australia's Population and Environment Debates', Australian Geographer, 44, 2013, pp. 41-62; N.Klocker, S.Toole, A.Tindale and S-M.Kerr, 'Ethnically Diverse Transport Behaviours: An Australian Perspective’, Geographical Research, 53, 2015, pp. 393-405; G.Waitt and L.Welland, 'Water, Skin and Touch: Migrant Bathing Assemblages', Social \& Cultural Geography. Epub ahead of print 6 July 2017. DOI: 10.1080/14649365.2017.1347271.

\section{Author biographies}

Natascha Klocker is a senior lecturer in the School of Geography and Sustainable Communities at the University of Wollongong, Australia. Her research focuses on equity, discrimination and inclusion/exclusion - most often explored through the lens of migration and ethnic diversity. Natascha's current research explores the environmental and agricultural knowledges, capacities and contributions of migrants and refugees. She can be contacted via email: natascha_klocker@uow.edu.au

Paul Mbenna is an independent scholar, social worker and occasional researcher with the School of Geography and Sustainable Communities at the University of Wollongong. In addition to plastic bag footballs, he and Natascha have collaborated on research relating to child domestic work in Tanzania; and migrants, refugees and agriculture in Australia. He can be contacted via email: mbennap@yahoo.co.uk.

Chris Gibson is Professor of Human Geography and Director of the interdisciplinary research program, Global Challenges: Transforming Lives \& Regions, at the University of Wollongong, Australia. His present research projects explore geographies of making, and accompanying skills, labour tasks and dispositions with materials. He is currently Editor-inChief, Australian Geographer. He can be contacted via email: cgibson@uow.edu.au 